\title{
Violência juvenil: o desafio das práticas restaurativas no espaço escolar
}

\section{Youth violence: the challenge of restorative practices in school space Violencia juvenil: el desafío de las prácticas restaurativas en el espacio escolar}

CEZAR BUENO DE LIMA

Orcid Id: http://orcid.org/0000-0002-7725-010X

Pontifícia Universidade Católica do Paraná

\begin{abstract}
Resumo: $\mathrm{O}$ artigo questiona as representações coletivas e as práticas institucionais que tendem a naturalizar o fenômeno da violência, assim como a justificar ações verticalizadas e punitivas de poder na composição dos conflitos juvenis no âmbito escolar. Apresenta alternativas teórico-metodológicas que ampliam o significado do termo violência, relacionando-o à teoria dos Direitos Humanos, à democracia deliberativa e às práticas restaurativas. Sugere a importância da construção de estratégias dialogadas, participativas e deliberativas de mediação e prevenção pacífica dos conflitos no espaço escolar.
\end{abstract}

Palavras-chave: Violência; Juventude; Direitos Humanos; Práticas Restaurativas

\begin{abstract}
The article questions the collective representations and institutional practices that tend to naturalize the phenomenon of violence, as well as to justify verticalized and punitive actions of power in the composition of the juvenile conflicts in the school context. It presents theoretical-methodological alternatives that amplify the meaning of the term violence, relating it to Human Rights theory, deliberative democracy, and restorative practices. It suggests the importance of the construction of dialogic, participatory and deliberative strategies for mediation and peaceful conflict prevention in the school space.
\end{abstract}

Keywords: Violence. Youth; Human Rights; Restorative Practices.

Resumen: El artículo cuestiona las representaciones colectivas y las prácticas institucionales que tienden naturalizar el fenómeno de la violencia así como justificar acciones verticalizadas y punitivas de poder en la composición de los conflictos juveniles en el ámbito escolar. Presenta alternativas teórico-metodológicas que amplian el significado del término violencia, relacionándolo a la teoría de los Derechos Humanos, a la democracia deliberativa y a las prácticas restaurativas. Sugiere la importancia de la construcción de estrategias dialogadas, participativas y deliberativas de mediación y prevención pacifica de los conflictos en el espacio escolar.

Palabras clave: Violencia; Juventud; Derechos Humanos; Prácticas Restaurativas 


\section{INTRODUÇÃO}

O propósito do artigo é problematizar a percepção social dominante que tende a reduzir, em diferentes espaços, a compreensão de fenômenos sociais complexos como a violência ao paradigma do direito penal culpabilizador e retributivo, os Direitos Humanos a veredictos desabonadores que induzem uma falsa percepção coletiva de que tais direitos protegem mais os violadores da lei que as pessoas de bem e, por fim, a democracia à sua dimensão meramente representativa canonizada pela teoria da circulação das elites e do exercício verticalizado do poder.

As orientações teórico-analíticas aqui utilizadas enfatizam que as formas de saber-poder consideradas relevantes e que orientam o curso da gestão dos conflitos e das ações educativas podem suscitar, entre os adolescentes e jovens pobres e em situação de vulnerabilidade social, manifestações de indiferença, quando não de resistência, a projetos político-pedagógicos que não vislumbram a construção de estratégias de participação direta dos estudantes nas situações problemáticas que lhes dizem respeito.

Uma das hipóteses para contornar ou mitigar o descompasso entre as pretensões normativas da escola e as aspirações juvenis, no campo da mediação de conflitos, sugere a necessidade de a escola abrir-se à incorporação de novos conhecimentos e sensibilidades a respeito dos adolescentes e jovens para além daqueles que costumam defini-los como fonte de imaturidade, problema e desordem social. A utilização de aportes teórico-metodológicos com foco na realização de estudos de casos destinados a saber quem são esses adolescentes e jovens, o que eles têm a dizer, quais assuntos e pautas gostariam de propor e encaminhar, pode contribuir para conhecer e ressignificar os diferentes contextos que provocam situações de violência, diferentes interpretações dos Direitos Humanos e, ainda, socializar experiências empíricas que favoreçam a descentralização do poder, a abertura, o envolvimento e a coprodução de saberes e práticas comunitárias antirrepressivas de mediação e prevenção dos conflitos juvenis na escola.

No tocante ao método de exposição do trabalho, a primeira parte enfatiza o caráter complexo e multidimensional da violência, a segunda traz reflexões sobre a potencialidade dos Direitos Humanos na reversão da cultura punitiva e penalizadora que se espraia no espaço escolar e, por fim, a terceira parte ressalta o princípio educativo das práticas restaurativas nos processos de mediação e prevenção dos conflitos no espaço escolar. 


\section{VIOLÊNCIA, DIREITOS HUMANOS E PRÁTICAS RESTAURATIVAS: A IMPORTÂNCIA DE RESSIGNIFICAR CONCEITOS E FORMAS DE LIDAR COM OS CONFLITOS NO ESPAÇO ESCOLAR}

Nas sociedades contemporâneas, o caráter multidimensional da violência demanda esforços acadêmicos e estratégias político-institucionais que levem em conta a diversidade das situações reais e/ou potenciais que funcionam como disparadores de atos e comportamentos considerados violentos.

Embora não seja esse o espaço para expor e aprofundar a vasta literatura acerca do tema e da resiliência do paradigma da punição que o orienta, autores como Bourdieu (2012), Foucault (1987), Adorno (1996), Hulsman e Celis (1993), Garland (2008) e Bonamigo (2008), enfatizam o caráter polissêmico de violência cujos atos e comportamentos usualmente definidos como tais extrapolam definições e práticas tradicionalmente habituadas a interpretá-las como uma substância autoinscrita na consciência coletiva legitimadora de ações retributivas. A perspectiva analítica adotada procura mostrar que o termo violência demanda a construção de itinerários ideológicos e discursivos, correlações de forças políticas, acadêmicas, midiática etc., que incidem nos processos de construção de verdades e no funcionamento dos aparatos institucionais repressivos de poder incumbidos de exercer a violência física e simbólica considerada legítima.

A pluralidade dos problemas que se inscrevem no cotidiano das pessoas, nos grupos e classes sociais, nos seus territórios e suas instituições desafia alternativas teórico-políticas alinhas à desconstrução e circulação de verdades que rotulam determinados atos e comportamentos como violentos per si e conferem o monopólio do saber de perícia do Estado/peritos universitários no desfecho de tais atos e comportamentos. Essa tendência, aliás, mostra o quão as instituições, as autoridades e os peritos sociais modernos, produtores e certificadores de saberes específicos, incluindo o campo acadêmico-institucional de interpretação dos Direitos Humanos, permanecem chancelando a "redução do conhecimento à ciência, da política ao Estado, e do direito à lei” (ESCRIVÃO FILHO; SOUZA JUNIOR, 2016, p.14).

O quadro abaixo apresenta uma descrição ampliada do termo violência no intuito de postular a complexidade acadêmica, política e institucional sobre o tema, assim como pensar a importância da pesquisa de campo, com foco em estudos de casos, e iniciativas político-pedagógicas interessadas em compreender e problematizar conceitos e práticas essencialistas e reducionistas acerca da violência. 


\section{Quadro 1 - Tipologia das violências passíveis de observação nas sociedades contemporâneas}

\begin{tabular}{|c|c|c|c|c|c|}
\hline & Violência coletiva & $\begin{array}{l}\text { Violência } \\
\text { institucional }\end{array}$ & Violência estrutural & Violência cultural & Violência individual \\
\hline $\begin{array}{c}\text { FORMAS } \\
\text { DE VIOLÊNCIA }\end{array}$ & $\begin{array}{l}\text { - Participação } \\
\text { direta e ativa da } \\
\text { sociedade; } \\
\text { - Linchamento } \\
\text { popular; } \\
\text { - Bullying. }\end{array}$ & $\begin{array}{l}\text { - Instituições } \\
\text { legitimadas para } \\
\text { o uso da força } \\
\text { (tecnologia de } \\
\text { destruição); } \\
\text { - Estado policial; } \\
\text { - Instituição } \\
\text { escolar. }\end{array}$ & $\begin{array}{l}\text { - Desigualdade } \\
\text { social: recursos, } \\
\text { poder e decisão } \\
\text { (sobre a forma de } \\
\text { distribuí-los); } \\
\text { - reprodução da } \\
\text { fome, miséria, } \\
\text { submissão étnica, } \\
\text { etc. }\end{array}$ & $\begin{array}{c}\text { - Exercício } \\
\text { individual ou } \\
\text { coletivo } \\
\text { (uso da diferença } \\
\text { para inferiorizar ou } \\
\text { negar a identidade } \\
\text { do outro). }\end{array}$ & $\begin{array}{l}\text { - Manifestação } \\
\text { interpessoal } \\
\text { da violência } \\
\text { (contra crianças, } \\
\text { adolescentes, } \\
\text { jovens (violência } \\
\text { comum); } \\
\text { - Narcotráfico } \\
\text { (violência } \\
\text { organizada). }\end{array}$ \\
\hline
\end{tabular}

Elaboração: Lima (2019)

Para Bonamigo, a alusão ao termo violência não pode estar separada do contexto que "implica referenciar valores e normas" que se modificam "no tempo e no espaço das relações sociais". Nas formações sociais do passado, por exemplo, o sentido atribuído à violência estava mais diretamente associado à "existência de dano físico" ao passo que, nas sociedades atuais, a emergência de novas sensibilidades amplia o significado e o alcance do termo, vinculando-o às práticas de "discriminação por cor, sexo, idade, etnia, religião, escolha sexual; situações de constrangimento, exclusão ou humilhação". A ampliação dos provedores de significados alusivos à violência sugere que os processos de investigação sobre o tema não devem ser "determinados a priori, mas apreendidos nos coletivos onde se desenvolve a pesquisa"(BONAMIGO, 2008, p. 206).

A realização de um diagnóstico com foco nas múltiplas faces da violência no espaço escolar, envolvendo a participação amostral de 6.709 alunos de 129 escolas do ensino fundamental II, ensino médio e Educação de Jovens e Adultos (EJA), distribuídos em 6 capitais do país (Belém, BH, Fortaleza, Maceió, Salvador, São Luís e Vitória) em 2016, mostra como os estudantes pensam sobre a violência. 


\section{Tabela 1 - Avaliação atribuída pelos alunos às escolas, incluindo situações em que estes presenciaram situações de violência no espaço escolar (2016)}

\begin{tabular}{|c|c|c|c|c|c|c|c|c|}
\hline $\begin{array}{c}\text { Tipos de } \\
\text { violências } \\
\text { nas escolas }\end{array}$ & Belém & $\begin{array}{c}\text { Belo } \\
\text { Horizonte }\end{array}$ & Fortaleza & Maceió & Salvador & $\begin{array}{c}\text { São } \\
\text { Luís }\end{array}$ & Vitória & Total (\%) \\
\hline Brigas & 13,5 & 13,8 & 15,3 & 19,1 & 16,8 & 14 & 13,5 & 15,1 \\
\hline Xingamentos & 11,9 & 12,9 & 15,0 & 15,8 & 16,6 & 15,0 & 14,0 & 14,4 \\
\hline Pichação & 13,3 & 10,0 & 11,7 & 13,0 & 5,3 & 12,2 & 12,1 & 11,0 \\
\hline Roubos / furtos & 11,9 & 10,3 & 10,4 & 10,3 & 10,4 & 11,2 & 6,8 & 10,1 \\
\hline Ameaças & 7,1 & 7,9 & 7,6 & 9,9 & 7,8 & 6,6 & 7,7 & 7,8 \\
\hline $\begin{array}{c}\text { Cyberbullying } \\
\text { (zoar, ameaçar } \\
\text { o xingar pela } \\
\text { internet) }\end{array}$ & 6,8 & 8,5 & 9,3 & 8,3 & 8,6 & 6,9 & 6,4 & 7,2 \\
\hline Discriminação & 5,6 & 6,9 & 7,0 & 4,1 & 8,0 & 6,9 & 7,3 & 6,5 \\
\hline $\begin{array}{c}\text { Uso de drogas } \\
\text { ilicitas (maconha, } \\
\text { cocaina, crack, } \\
\text { cola etc.) }\end{array}$ & 6,6 & 6,5 & 6 & 3,7 & 5,9 & 5 & 6,5 & 5,7 \\
\hline Tráfico de drogas & 2,6 & 3,0 & 2,3 & 1,6 & 1,9 & 2,5 & 3,3 & 2,4 \\
\hline
\end{tabular}

Fonte: Abramovay, (2016, p.31-33).

Elaboração: Lima (2019).

Dentre os tipos de violência que os estudantes afirmaram presenciar nas escolas, os acontecimentos envolvendo brigas, xingamentos, ameaças, cyberbullying e discriminação representam 55\% dos casos; as situações de roubos e furtos, 10,2\%; e as de tráfico e uso de drogas, $8,1 \%$. Em relação às respostas juvenis, interessa aqui refletir como essas informações, para efeito de mediação e prevenção pacífica dos conflitos no espaço escolar, poderiam ser lidas e interpretadas como problemas indesejados, considerando "a complexidade dos seres, [...] suas relações [e] experiências vividas”. A promoção de políticas públicas alinhadas a perspectivas analíticas mais amplas de violência, Direitos Humanos e democracia sugeridas neste artigo, poderia contribuir para evitar que situações como as de xingamentos, brigas juvenis e, em certos casos, furtos e tráfico de drogas nas escolas fossem submetidas à bitola criminalizadora, assim como à sua "máquina de punir herdada de séculos passados", que reduz a complexidade dos conflitos ao tripé violência, crime e inevitabilidade do castigo (HULSMAN; CELIS, 1993, p. 56). A indagação dos autores acerca do caráter simplificador que nutre o paradigma punitivo reforça a necessidade de enfatizar o papel educativo, participativo e deliberativo de novas estratégias de mediação, prevenção de conflitos e de enraizamento da cultura dos Direitos Humanos no cotidiano escolar. 


\section{O PAPEL DOS DIREITOS HUMANOS NA REVERSÃO DA CULTURA PUNITIVA E RETRIBUTIVA NO ESPAÇO ESCOLAR}

O ponto de vista aqui adotado enfatiza a necessidade de pensar os Direitos Humanos a partir da realidade econômica, social e política dos indivíduos, dos grupos, das classes sociais, enfim, da ação humana que assume a perspectiva que os direitos podem ser construídos "[...] desconstruídos, reconhecidos e negados, efetivados e violados na dialética da história”. (ESCRIVÃO FILHO; SOUZA JUNIOR, 2016, p. 31). As lutas que originaram a normatização dos direitos das mulheres, das infâncias e juventudes, dos idosos, entre outros, mostram o caráter eminentemente histórico, contextual e não linear dos Direitos Humanos. Entretanto, uma rápida incursão na história da modernização ocidental testemunha a primazia dos direitos civis e políticos sobre os direitos econômicos, sociais e culturais os quais permanecem como vagas promessas legais de materialização político-institucional.

Para Santos, a invenção das sociedades ocidentais fundamentadas na existência de indivíduos racionais e livres, portadores de interesses egoístas, sujeitos de si e diretamente responsáveis pelas suas escolhas, suas virtudes e seus fracassos, complementadas pelo discurso de normatividade apolítica dos Direitos Humanos, é funcional aos modelos de economia e de Estado neoliberal pelos motivos que seguem:

[...] sendo todos os indivíduos chamados, se não mesmos forçados, a ser autônomos, a sociedade pode legitimamente abandoná-los se os seus fracassos forem considerados como o resultado de inépcia no exercício dessa autonomia. Apolítica, pelo fato de o imenso poder desta ideia consistir na promoção de um conceito de poder tão imensamente fragmentado, como disseminado numa rede virtualmente infinita de interações entre indivíduos competindo por recursos escassos e recompensas no mercado (SANTOS, 2014, p. 9-10).

Em relação aos países da América Latina, Quijano amplia o olhar crítico sobre os Direitos Humanos ao considerar que a modernidade ocidental, berço das modernas declarações de direitos, se impôs de cima para baixo e imprimiu um "novo padrão de poder mundial". O autor enfatiza, em especial, o código diferencial centrado na "ideia de raça" e a conversão das "formas históricas de trabalho, de seus recursos e de seus produtos, subordinados ao capital e ao mercado mundial", para mostrar o peso destes elementos na formação de países, como o Brasil, marcados pela dominação colonial, escravidão e exclusão social. (QUIJANO, 2005, p. 117). 
No Brasil, as cifras oficiais de letalidade urbana evidenciam que a maioria dos autores e vítimas de violência provêm de locais habitados por famílias pobres e, preferencialmente, da cor negra ou parda. Em muitas situações, as pessoas que habitam os territórios marcados pelo estigma da violência são tomadas por "um surdo sentimento de culpabilidade e vergonha, cujo peso subjacente" força os moradores a dissimularem o lugar onde residem e "evitarem visitas de amigos e familiares" (WACQUANT, 2016, p. 5).

Em relação aos adolescentes e jovens envolvidos em casos de violência, dados do IPEA e do Fórum Brasileiro de Segurança Pública (FBSP) apontam, desde 1980, "um processo gradativo de vitimização letal da juventude". Entre 2005 e 2015 o Brasil contabilizou "um aumento de 17,2\% na taxa de homicídio de indivíduos entre 15 e 29 anos" (IPEA, 2017, p. 25). O penúltimo levantamento disponibilizado pelo Sistema Nacional de Atendimento Socioeducativo (Sinase) mostra que, entre 2009 e 2016, a taxa de encarceramento juvenil subiu de 19.940 para 25.929 adolescentes em regime de internação, internação provisória e semiliberdade (BRASIL, SINASE, 2016, p. 4). Nesse contexto de expansão da letalidade e de outras formas de violência que reverberam em taxas de aprisionamento alarmantes, proposições teórico-empíricas de defesa e promoção das políticas públicas sociais são desafiadas a questionar e afirmar, dentro e fora do espaço acadêmico, o caráter de indivisibilidade, interdependência e integralidade dos civis, políticos, econômicos, sociais e culturais.

No plano da microrrealidade, as práticas sociais orientadas por relações de interesse, poder e luta por reconhecimento impactam nãos apenas as maneiras de ver e interpretar determinadas narrativas em torno dos Direitos Humanos, mas também as pretensões normativas e o funcionamento das instituições educacionais. A tipologia descrita abaixo, condicionada à necessidade de análise e compreensão dos sujeitos, das instituições e dos seus territórios locais, contribui para a promoção de estratégias pedagógicas contextualizadas de ressignificação dos Direitos Humanos junto a determinados públicos-alvo. 


\section{Quadro 2 - Descritivo dos Direitos Humanos passíveis de observação no espaço escolar e no entorno das escolas (bairro)}

\begin{tabular}{|c|c|c|}
\hline \multirow{5}{*}{$\begin{array}{l}\text { DIREITOS } \\
\text { HUMANOS }\end{array}$} & Direitos civis & $\begin{array}{l}\text { Direitos à/ao: } \\
\text { Vida; } \\
\text { Liberdade de consciência e de crença; } \\
\text { Livre pensamento; } \\
\text { Intimidade, a vida privada, a honra; } \\
\text { Residência como asilo inviolável; } \\
\text { Contra ilegalidade ou abuso de poder; } \\
\text { Integridade física e moral (preso); } \\
\text { Registro civil e certidão de óbito (gratuitos). }\end{array}$ \\
\hline & Direitos Políticos & $\begin{array}{l}\text { Participação no poder (governo e sociedade); } \\
\text { Soberania popular (voto, plebiscito, referendo, iniciativa popular); } \\
\text { Manifestações políticas; } \\
\text { Organizar partidos; } \\
\text { Votar e ser votado. }\end{array}$ \\
\hline & Direitos Sociais & $\begin{array}{l}\text { Educação; } \\
\text { Saúde; } \\
\text { Alimentação; } \\
\text { Trabalho; } \\
\text { Moradia; } \\
\text { Transporte, previdência social, proteção à maternidade e à infância, etc. }\end{array}$ \\
\hline & $\begin{array}{l}\text { Direitos } \\
\text { Econômicos }\end{array}$ & $\begin{array}{l}\text { Produção, distribuição e consumo da riqueza; } \\
\text { Liberdade de escolha de trabalho; } \\
\text { Renumeração justa, sem distinção de sexo (homens e mulheres); } \\
\text { Higiene, segurança, promoção (por desempenho e tempo de serviço); } \\
\text { Fundar sindicato, fazer greve; } \\
\text { Segurança social. }\end{array}$ \\
\hline & Direitos Culturais & $\begin{array}{l}\text { Reconhecimento da identidade do indivíduo e o aproveitamento de suas qualidades; } \\
\text { Acesso às fontes da cultura nacional (bens de natureza material e imaterial); } \\
\text { Diversidade étnica e regional; } \\
\text { Manifestações das culturas populares, indígenas e afro-brasileiras; } \\
\text { Educação e formação de qualidade que respeite plenamente sua identidade cultural. }\end{array}$ \\
\hline
\end{tabular}

Fonte: Brasil, (2010); Brasil. Constituição (1988); Conferência Mundial Direitos Humanos de Viena, (1993); ONU, (1948), Pacto dos Direitos Econômicos, Sociais e Culturais (1966).

Elaboração: Lima (2019).

O modelo descritivo acima pode ser utilizado como estratégia de sensibilização e ampliação da percepção juvenil acerca das diferentes dimensões dos Direitos Humanos. O envolvimento direto dos sujeitos nos processos de produção e ressignificação dos valores e normas permite dimensionar, por exemplo, até que ponto os propósitos oficiais de solução dos conflitos, ou mesmo os modelos de ensino-aprendizagem dirigidos aos jovens estudantes, podem mostra-se incongruentes com as expectativas que estes formulam em termos de eficácia, interesse e legitimidade social. 


\section{OS JOVENS COMO SUJEITOS QUE INTERPRETAM SEU MUNDO E FAZEM EMERGIR NOVAS PRÁTICAS DE SOCIABILIDADE NA ESCOLA}

A compreensão de como os jovens pensam, agem e definem seus projetos de vida, contribui para evitar que as instituições e suas respectivas autoridades recorram a ações pedagógicas sedimentadas em concepções essencialistas e tradicionais de família, autoridade, ensino-aprendizagem, violência, trabalho, entre outros, em especial quando a sociedade e suas instituições educacionais se deparam com incertezas e crises dos procedimentos usuais de resolução dos conflitos $^{1}$.

Em relação às constelações familiares, o ideal de família nuclear burguesa, considerado ainda hoje como fonte privilegiada de controle social, vem perdendo centralidade. Crises econômicas, opções culturais de postergar casamentos, ter filhos ou simplesmente de viver sozinho, configurações homoafetivas etc. redefinem e volatilizam as noções de família estruturada, em especial, as formas tradicionais de casamentos, dando lugar a uniões estáveis e outras formas emergentes de configuração familiar. No caso das famílias que possuem filhos/as adolescentes e jovens, os interesses e valores idealizados pelos pais já não servem como sólida referência à sua prole. No lugar dos costumes e rituais de iniciação e passagem para a vida adulta, impõem-se novas formas de relações pautadas por interesses econômicos e socioculturais que apelam à formação de identidades grupais fluídas, delimitadas e autorreferenciais.

Paralelo a isso, as desigualdades concernentes à apropriação e distribuição do capital econômico-financeiro e educacional potencializam a contradição entre aquilo que pais, mães e responsáveis vislumbram para os seus filhos, em termos de expectativa profissional, sucesso e prestígio social, e os inúmeros entraves cotidianos que muitos adolescentes e jovens terão de enfrentar uma vez que estes têm sido, cada vez mais, confrontados com a recorrência de crises econômicas, precarização do ensino, dificuldades de conclusão dos estudos, ameaça do desemprego ou do subemprego.

Em relação às classes sociais, os filhos das famílias ricas e classes médias herdam estilos de vida, tecem círculos de amizade, frequentam as mesmas escolas e, em consequência, agregam heranças imateriais na forma de "casamentos

1 As noções em questão aparecem como resultados de projetos de pesquisa PIBIC, artigos científicos e demais produções acadêmicas anteriores, sob minha orientação e autoria. 
vantajosos, amizades duradouras e acesso a relações sociais privilegiadas". A apropriação desse conjunto diferencial de capital cultural os ajudará a promover a “reprodução ampliada do próprio capital material”. (SOUZA, 2009, p.19).

No que concerne ao valor-trabalho, ainda que seja cada vez mais difícil dissociar a relação ensino-aprendizagem da qualificação para o mundo do trabalho, é preciso lembrar que a perspectiva moral dominante que atribui valor intrínseco à categoria trabalho não deve subestimar a importância hierárquica que a sociedade, seu respectivo modo de produção e sua cultura aquisitiva atribuem às diferentes profissões. No atual cenário urbano, o fetiche da mercadoria tem sido mobilizado para atender necessidades subjetivas cada vez mais distintas no campo das emoções, das identidades e dos relacionamentos. Ao mesmo tempo, a imposição dos processos de robotização da produção, de arranjos organizacionais flexíveis e da desformalização jurídica de proteção ao trabalho fazem erodir a perspectiva de estabilidade no emprego e generalizar a oferta de trabalho temporário, terceirizado, precário e intermitente.

No caso dos adolescentes e jovens brasileiros, inseridos em um contexto de desigualdade, violência e exclusão social, a maioria permanece à margem das opções político-legais consideradas legítimas de acesso e aquisição de capitais que abrem o caminho das melhores escolas, dos melhores empregos e do sonho de mobilidade social ascendente. Logo, é compreensível que muitos adolescentes e jovens que se veem na iminência de não realizar seus sonhos dentro da moldura político-institucional vigente optem por alternativas ilegais de inclusão e ascensão social, mesmo que para isso formulem a consciência de trilhar o caminho da ilegalidade que, muitas vezes, os leva ao encarceramento prisional.

A tabela abaixo descreve os perfis etários e de escolaridade dos adultos e jovens encarcerados no Brasil.

\section{Tabela 2 - Encarceramento de Adultos e jovens no Brasil}

\begin{tabular}{|c|c|c|c|c|}
\hline \multicolumn{3}{|c|}{ Ano base } & 2016 \\
\hline \multicolumn{4}{|c|}{ Total de pessoas adultas privadas de liberdade no Brasil } & 726.712 \\
\hline \multirow{4}{*}{ Adultos } & Idade & $\%$ & Escolaridade $^{2}$ & $\%$ \\
\cline { 2 - 5 } & 18 a 24 anos & $30 \%$ & Alfabetizado (sem cursos regulares) & $6 \%$ \\
\cline { 2 - 5 } & 25 a 29 anos & $25 \%$ & Fundamental incompleto & $51 \%$ \\
\cline { 2 - 5 } & 30 a 34 anos & $19 \%$ & Fundamental completo & $14 \%$ \\
\cline { 2 - 5 } & 35 a 45 anos & $19 \%$ & Médio incompleto & $15 \%$ \\
\cline { 2 - 5 } & 46 ou mais & $8 \%$ & Médio completo & $9 \%$ \\
\hline
\end{tabular}

Escolaridade ${ }^{2}$ 
Tabela 2 - Encarceramento de Adultos e jovens no Brasil

\begin{tabular}{|c|c|c|c|c|}
\hline \multirow{7}{*}{ Adolescentes } & \multicolumn{3}{|c|}{ Total de adolescentes em atendimento socioeducativo no Brasil ${ }^{3}$} & $26.450^{4}$ \\
\hline & Idade & $\%$ & Escolaridade $^{5}$ & $\%$ \\
\hline & 16 e 17 anos & $57 \%$ & Analfabetos & $8 \%$ \\
\hline & 18 a 21 anos & $23 \%$ & Não frequentam a escola & $57 \%$ \\
\hline & 14 a 15 anos & $17 \%$ & $\begin{array}{l}\text { Idade média de interrupção dos } \\
\text { estudos }\end{array}$ & 14 anos \\
\hline & 12 a 13 anos & $2 \%$ & $\begin{array}{l}\text { Idade média de cometimento do } \\
\text { primeiro ato infracional }\end{array}$ & 15 anos \\
\hline & Não especifica idade & $1 \%$ & $\begin{array}{l}\text { Adolescentes que cometeram o } \\
\text { primeiro ato infracional aos } 15 \text { anos }\end{array}$ & $47 \%$ \\
\hline
\end{tabular}

Fonte: IPEA, (2017); Brasil, (2016); Brasil, (2012).

Elaboração: Lima (2019).

Uma simples observação dos perfis de idade, escolaridade e outras vulnerabilidades inscritas nas biografias dos adolescentes e jovens em conflito com a lei, encarcerados ou sob outras formas de controle à céu aberto, evidencia o quão a política criminalizadora da questão social representa uma ameaça perturbadora no contexto das sociedades que se atribuem democráticas. Como reverter ou mitigar essa tendência de judicialização criminalizadora da vida social?

\section{AS PRÁTICAS RESTAURATIVAS COMO PRINCÍPIO EDUCATIVO DE GESTÃO DOS CONFLITOS NO ESPAÇO ESCOLAR}

Embora não haja consenso a respeito da definição conceitual de justiça restaurativa, diversos autores como Zehr (2008), De Vitto (2005), Lima e Silveira (2017) convergem ao afirmar que a expressão justiça restaurativa surgiu em 1977 para definir, em oposição à ideia abstrata de crime e caráter retributivo da pena, inscritos no direito penal convencional, os atos de agressão como um acontecimento que vincula material e/ou simbolicamente as figuras do agressor, da vítima e da comunidade. Em consequência, a busca de soluções restaurativas requer o empoderamento das partes envolvidas em conflitos, desde que estas se disponham a levar e participar espontaneamente dos procedimentos informais restaurativos em espaços comunitários, com a presença de mediadores/

\footnotetext{
3 Restrição de liberdade (internação, internação provisória e semiliberdade).

4 Outras modalidades: 521 adolescentes (atendimento inicial, internação sanção).

5 Os dados oficiais de 2016 não apresentam informações consolidadas de escolarização dos adolescentes em regime de internação. A opção aqui foi utilizar informações educacionais aproximadas, extraídas do levantamento encomendado pelo Conselho Nacional de Justiça (CNJ/2012).
} 
facilitadores, preferencialmente distantes do rito burocrático e solene que configura a arquitetura do Poder Judiciário. No plano normativo, a Organização das Nações Unidas (ONU) busca convencer, desde 2002, diversos países a adotarem princípios e métodos de justiça restaurativa como forma de resolver conflitos, restaurando o dano causado à vítima e evitando estigmatizar a figura do agressor. O princípio não punitivo da responsabilização se realiza por meio da aprendizagem de técnicas de mediação, conciliação, transação etc., priorizando o atendimento das necessidades individuais e coletivas, além de promover a reintegração da vítima e do ofensor.

Em termos sociológicos, os valores e as práticas restaurativas não se confundem com o Estado e as instituições sob seu controle. Santos (1996) lembra que as sociedades complexas possuem diversos mecanismos de resolução de litígios, assim como instâncias mediadoras que incluem a família, os vizinhos, as associações comunitárias, os professores, os estudantes etc. A transformação dos litígios sociais em litígios judiciais é apenas uma alternativa entre outras e não é, de modo algum, a mais provável. (SANTOS, 1996, p. 50-52).

Embora a justiça restaurativa ressalte a importância do encaminhamento e solução não punitiva dos conflitos (crimes), é preciso reconhecer que, do ponto de vista da organização institucional e criminal do Estado, esse modelo permanece subordinado à centralidade das instituições estatais que, quase sempre, atribuem aos operadores da justiça como o Ministério Público e o Poder Judiciário o poder de dar a última palavra no desfecho dos conflitos. Nesses termos, a justiça restaurativa corre o risco de reproduzir a centralidade verticalizadora do Estado penal e funcionar apenas como um mecanismo alternativo e complementar de gestão dos conflitos no âmbito da justiça criminal, sob o controle disciplinar e culpabilizador das instituições oficiais.

Sob este ponto de vista, é preciso questionar o modo de recepção da justiça restaurativa nos espaços institucionais que, em princípio, não lidam com os mesmos problemas, os mesmos sujeitos e os mesmos objetivos que demandam o cotidiano dos aparatos à serviço da judicialização dos conflitos. Sob esse aspecto, a opção pela utilização do termo práticas restaurativas no espaço escolar diz respeito não apenas à opção por aportes teórico-valorativos que induzem diferentes possibilidades de abordagem institucional sobre o tema, mas às configurações das instituições, dos sujeitos e da própria natureza dos conflitos que ocorrem no espaço escolar.

No campo da justiça criminal (Direito Penal, Polícia, Ministério Público, Judiciário e Sistema Penitenciário) é possível afirmar, por exemplo, que os atores que a compõem têm sido instituídos e educados para ver, pensar e manejar uma 
série de conflitos, fundamentando-se nas noções formais e abstratas de crime, criminoso, pena, prisão, etc., e, em muitos casos, mentalmente conformados à prescrição da pedagogia jurídico-penal retributiva e individualizante da punição.

As instituições educacionais, por seu turno, estão ligadas a percursos político-pedagógicos que demandam formação humanista e aprendizagem profissional de adolescentes, jovens e adultos. Enquanto instituição formal de controle, o papel do sistema de justiça criminal é reagir, intervir, julgar e retirar de circulação determinadas pessoas acusadas de violar a lei e cometer crimes contra a propriedade, determinadas pessoas e grupos sociais, ou seja, contra a própria sociedade. No tocante à instituição escolar, sua missão é, ao contrário, educar adolescentes, jovens e adultos e prepará-los para o exercício da cidadania. O papel da escola é, enfim, socializar e difundir conhecimentos humanos e técnicocientíficos de modo que o conjunto das aprendizagens em questão, subordinado a valores democráticos e plurais, mostre-se capaz de incutir entre os educandos a importância do reconhecimento de certos valores e regras, como o direito à liberdade, à diferença, a autonomia, a superação da desigualdade e o respeito mútuo.

Outro ponto de reflexão em torno das práticas restaurativas nas escolas comporta a seguinte indagação: se essas, em princípio, não lidam com os mesmos sujeitos, os mesmos conflitos e os mesmos objetivos que demandam a intervenção do sistema de justiça criminal, como justificar a transposição de mecanismos alternativos de solução dos conflitos, oriundos do sistema penal, ao campo educacional? Embora tais indagações não comportem respostas conclusivas, um dos objetivos deste artigo é chamar atenção para a influência do paradigma da justiça criminal, em especial, das noções formais de crime, criminoso, culpa, caráter retributivo e individualizante da pena no cotidiano das instituições educacionais.

Nas sociedades contemporâneas, o direito penal culpabilizador e retributivo tem sido utilizado como o lócus conversor de uma multiplicidade de problemas indesejados. Na medida em que a perspectiva penalizadora de gestão dos conflitos se torna hegemônica, a pedagogia punitiva, culpabilizadora, retributiva e individualizante tende a espraiar-se para outros domínios sociais incluindo o campo educacional.

Considerando o fato de as instituições educacionais utilizarem mecanismos formais de controle como os conselhos de classe, sistemas formais de avaliação ou, ainda, a crença meritocrática como critério para premiar talentos e punir fracassos, tais instituições tendem a produzir, entre os estudantes, efeitos análogos ao modelo de funcionamento da justiça criminal. Sob esse ponto, escreve Baratta, a instituição escolar enquanto aparato de "socialização da cultura dominante das camadas médias" pode fazer recair o expediente da punição, 
principalmente sobre os jovens provenientes dos estratos inferiores da sociedade, aplicando "sanções negativas" e excludentes aos alunos que "apresentam notável dificuldade de se adaptarem a um mundo em parte estranho a eles, e a assumirem [...] modelos comportamentais e linguísticos" estranhos aos seus contextos de referência familiar e social. Segundo o autor, a função simbólica da punição escolar, dirigida "aos maus alunos" pode extrapolar o que os estudantes realmente fizeram por merecer, além de "transferir o mal e a culpa sobre uma minoria estigmatizada". Neste caso, a estratégia da punição escolar funciona como fator de integração, recompensa e "convalidação [...] dos modelos de comportamentos não estigmatizados" da maioria (BARATTA, 2002, p. 173-175). Ao mencionar o cotidiano das instituições educacionais, Souza argumenta que estas operam de modo análogo:

[...] à prisão. [Em muitas situações] a escola vivenciada pelos sujeitos pesquisados é um instrumento de controle, penalização e distinção. [Uma instituição que] centraliza a aprendizagem em detrimento das dimensões fundamentais dos seres humanos, ignora a historicidade dos sujeitos, as condições materiais e psicossociais de sua existência e os entornos escolares onde estes sujeitos se encontram em constante embate (SOUZA, 2016, p. 167-169).

De acordo com os argumentos acima, a escola perde sua missão democrática e transformadora, aproximando-se da rotina de instituições portadoras de uma "cultura hierárquica, autoritária e punitiva", além de disseminar entre os estudantes valores e métodos de lidar com "os conflitos internos" análogos àqueles "tratados pela ordem retributiva no Direito Penal" (Lima e Américo Jr, 2015, p. 2016).

As Diretrizes Curriculares Nacionais Gerais da Educação Básica, que preveem a participação coletiva na elaboração do projeto político-pedagógico das escolas e consideram que estas "assim como outras instituições sociais, têm um papel fundamental a desempenhar na garantia do respeito aos Direitos Humanos", assumem feições meramente ritualísticas e/ou o destino de normas invisibilizadas no cotidiano escolar. (BRASIL, 2013, p. 164).

As recomendações do Programa Nacional de Direitos Humanos (PNDH3) no fomento de "iniciativas de mediação e conciliação, estimulando a resolução de conflitos por meios autocompositivos, voltados à maior pacificação social e menor judicialização" abrem caminho para mostrar, do ponto de vista das práticas restaurativas, que o papel da escola deve ir além da proposição pacífica de mecanismos para dirimir "conflitos internos". (BRASIL, 2010, p.144-145)

As referências normativas acima corroboram que missão desafiadora da escola é, antes, problematizar, contextualizar e disseminar a pluralidade de conceitos e valores atinentes à "democracia, igualdade, respeito", participação e 
deliberação (Lima e Américo Jr, 2015, p. 217). Conforme esse entendimento, a práticas restaurativas abrem, entre os educadores, educandos e a comunidade, perspectivas inovadoras voltadas não apenas à proposição pacífica de solução dos conflitos, mas à coprodução coletiva de diálogos participativos, democráticos, inclusivos e deliberativos direcionados à construção de aprendizagens significativas e à promoção dos Direitos Humanos.

\section{CONSIDERAÇÕES FINAIS}

Sem menosprezar os impactos da atual conjuntura caracterizada pela emergência de plataformas políticas autoritárias, desigualdade econômica, violência e exclusão social, as quais reverberam em práticas educacionais que reproduzem e legitimam modelos verticalizados e retributivos de gestão dos conflitos, a escola vê-se desafiada a problematizar, analisar, desnaturalizar e ressignificar a compreensão de temas como violência, Direitos Humanos e democracia e abrirse à emergência de novos conceitos que favoreçam a coprodução comunitária de saberes e práticas horizontais e restaurativas, orientadas pelo princípio da corresponsabilização e superação da cultura culpabilizadora e retributiva.

A compreensão e ressignificação desses temas se inscreve no contexto de uma realidade social configurada por desigualdades, lutas, conflitos e embates que confrontam e vislumbram distintos projetos de sociabilidade. Ao mesmo tempo, o contexto da microrrealidade dos sujeitos, de suas comunidades e de seus territórios requer a combinação entre aportes teóricos-metodológicos e a realização de estudos de casos que, em relação aos conflitos no espaço escolar, atribuam aos sujeitos envolvidos (adolescentes, jovens e suas famílias, professores, direção da escola e funcionários) a centralidade da fala e a inclusão de suas experiências de vida como estratégia de composição pacífica dos conflitos.

A opção por formas descentralizadas de poder, corresponsabilização individual e coletiva no encaminhamento e desfecho dos conflitos na escola representa uma alternativa acadêmico-política refratária à judicialização de atos e comportamentos por entender que estes podem e devem ser resolvidos de outra maneira. As possibilidades de êxito das práticas restaurativas no espaço escolar devem orientar-se pelo princípio da desjudicialização dos conflitos, uma vez que a peculiaridade do campo educacional jamais poderia tomar de empréstimo conceitos e métodos de intervenção oriundos do campo jurídico-criminal culpabilizador e retributivo. 
A investigação acadêmica com foco nas práticas restaurativas e no protagonismo dos adolescentes e jovens, assim como na comunidade interna e externa à escola pode oferecer não apenas novas perspectivas de resolução pacífica dos conflitos, mas a construção de itinerários democrático-participativos e deliberativos que favoreçam o enraizamento da cultura dos Direitos Humanos.

\section{REFERÊNCIAS}

ADORNO, S. F. de A. A gestão urbana do medo e da insegurança. 1996. 256 P. Tese (Livre docência) - Universidade de São Paulo. São Paulo: USP, 1996.

ABRAMOVAY, M. (Coord.). Diagnóstico participativo das violências nas escolas: falam os jovens. Rio de Janeiro: FLACSO - Brasil, OEI, MEC, 2016.

BARATTA, A. Criminologia crítica e crítica do direito penal: introdução à sociologia do direito penal. 3. ed. Rio de Janeiro: Revan, 2002.

BONAMIGO, I. S. Violências e contemporaneidade. Revista Katálysis, Florianóplis, v. 11, n. 2, p.204-213, jul./dez.2008.

BOURDIEU, P. A dominação masculina. Trad. Maria Helena. 11. ed. Rio de Janeiro: Bertrand Brasil, 2012.

BOURDIEU, Pierre. Razões práticas: sobre a teoria da ação. 8. ed. Campinas, SP: Papirus, 2007.

BRASIL. Conselho Nacional de Justiça. Panorama Nacional. A execução das medidas socioeducativas de internação: Programa Justiça ao Jovem. Brasília, 2012. Disponível em: https://www.cnj.jus.br/wp-content/uploads/2011/02/ panorama_nacional_doj_web.pdf. Acesso em: 12 abr., 2020.

BRASIL. Constituição (1988). Constituição da República Federativa do Brasil. Brasília, 1998. Disponível em: http://www.planalto.gov.br/ccivil_03/ constituicao/constituicao.htm. Acesso em: 12 abr., 2020.

BRASIL. Ministério da Educação. Secretaria de Educação Básica. Diretoria de Currículos e Educação Integral. Diretrizes curriculares nacionais gerais da educação básica. Brasília: MEC; SEB; DICEI, 2013. 
BRASIL. Ministério dos Direitos Humanos (MDH). Levantamento Anual SINASE 2016. Brasília: MDH, 2016. Disponível em: Disponível em: http:// www.mdh.gov.br/todas-as-noticias/2018/marco/Levantamento_2016Final.pdf. Acesso em: 12.abr., 2020.

BRASIL. Secretaria de Direitos Humanos da Presidência da República. Programa Nacional de Direitos Humanos (PNDH-3). rev. e atual. Brasilia: SDH/Pr, 2010.

CENTRO INTERNACIONAL DE INVESTIGAÇÃO E INFORMAÇÃO PARA A PAZ. O estado da paz e a evolução da violência. Campinas: Editora da Unicamp, 2002.

LIMA, C.B.; SILVEIRA, J. I. Práticas deliberativas e restaurativas em medidas socioeducativas: jovens como sujeitos de direitos. Argumentum., Vitória, v. 9, n. 3, p. 140-153, set./dez. 2017. Disponível em https://periodicos.ufes.br/ argumentum/issue/view/695. Acesso em: 12 abr., 2020.

LIMA, C.B.; AMÉRICO JUNIOR, Elston. Educar para a paz: práticas restaurativas na resolução de conflitos escolares. Rev. Educ. Movimento, Rio de Janeiro, v. 2, n. 3, págs. 195-224, 2015. Disponível em: https://periodicos.uff.br/ revistamovimento/issue/view/1728/showToc. Acesso em: 12 abr., 2020.

CONFERÊNCIA MUNDIALSOBREDIREITOS HUMANOS, 14-25 jun.1993, Viena. Declaração e programa de ação de Viena. Viena, 1993. Disponível em: <http://www.onumulheres.org.br/wp-content/uploads/2013/03/declaracao_ viena.pdf $>$. Acesso em: 28 jul. 2018.

DE VITTO, R. C. P. Justiça criminal, Justiça restaurativa e Direitos Humanos. In: SLAKMON, C.; DE VITTO, R. C. P.; PINTO, R. S. G. (Org.). Justiça restaurativa. Brasília: Ministério da Justiça; Programa das Nações Unidas para o Desenvolvimento, 2005. p.41-51.

ESCRIVÃO FILHO, A.; SOUZA JUNIOR, J. G. de. Para um debate teórico-conceitual e político sobre os Direitos Humanos. Belo Horizonte: D’PLÁCIDO, 2016.

FOUCAULT, M. Vigiar e punir: história da violência nas prisões. 23. ed. Petrópolis: Vozes, 1987. 
GARLAND, D. A cultura do controle: crime e ordem social na sociedade contemporânea. Trad. André Nascimento. Rio de Janeiro: Revan, 2008.

HULSMAN, L.; CELIS, J. B. de. Penas perdidas: o sistema penal em questão. Rio de Janeiro: Luam, 1993.

INSTITUTO DE PESQUISA E ESTATÍTICA APLICADA (IPEA). Ipea e FBSP divulgam o Atlas da Violência 2016. São Paulo, 2017. Disponível em: http://www.ipea.gov.br/portal/index.php?option=com_ content\&view $=$ article\&id $=27404$. Acesso em: 18 dez. 2018 .

ORGANIZAÇÃO DAS NAÇÕES UNIDAS (ONU). Assembleia Geral das Nações Unidas. Pacto Internacional sobre Direitos Econômicos, Sociais e Culturais. Rio de Janeiro, 1992. Disponível em: http://www.planalto.gov.br/ ccivil_03/decreto/1990-1994/d0591.htm. Acesso em: 12 abr., 2020.

ORGANIZAÇÃO DAS NAÇÕES UNIDAS (ONU). Resolução 12/2002: princípios básicos para utilização de programas de justiça restaurativa em matéria criminal. 2002. Disponível em: http://www.arcos.org.br/livros/ estudos-de-arbitragem-mediacao-e-negociacao-vol4/parte-vi-miscelanea/ nacoes-unidas-conselho-economico-e-social. Acesso em: 12 abr., 2020.

QUIJANO, A. Colonialidade do poder: eurocentrismo e América Latina. Buenos Aires: Consejo Latinoamericano de Ciências Sociales, 2005. Disponível em: <biblioteca.clacso.edu.ar/clacso/sur-sur/20100624103322/12_Quijano. pdf>. Acesso em: 12 abr., 2020.

SANTOS, B. de S. Se Deus fosse um ativista dos Direitos Humanos. 2. ed. São Paulo: Cortez, 2014.

SANTOS, B. S. et. al. Os tribunais nas sociedades contemporâneas. Revista Brasileira de Ciências Sociais, São Paulo, n. 30, p.29-59, fev.1996.

SOUZA, J. A ralé brasileira: quem é e como vive. Belo Horizonte: Ed. UFMG, 2009. 
SOUZA, L. A. de. Criminalidade juvenil: significados e sentidos para reincidência em medidas socioeducativas de internação no estado do Paraná. 2016. 251 p. (Dissertação) - Universidade Tecnológica Federal do Paraná. Programa de Pós-Graduação em Planejamento e Governança Pública, Curitiba, 2016.

WACQUANT, L. A estigmatização territorial na cidade da marginalidade avançada. Sociologia: Revista da Faculdade de Letras da Universidade do Porto, v.16, n. 1, p.1-13, jan. 2006. Disponível em: http://ojs.letras.up.pt/index. php/Sociologia/article/view/2365/2165. Acesso em: 12 abr., 2020.

ZEHR, H. Trocando as lentes: um novo foco sobre o crime e a justiça: justiça restaurativa. São Paulo: Palas Athena, 2008.

\section{Cezar Bueno de Lima}

Doutor em Ciências Sociais pela Pontifícia Universidade Católica de São Paulo. Professor do curso de graduação em Ciências Sociais da PUCPR. E-mail: c.bueno@pucpr.br 